\title{
Pengembangan oven dengan kontrol elektronik untuk peningkatan kapasitas dan kualitas produksi kue bolu
}

\author{
Muladi $^{1 \star}$, Yuni Rahmawati ${ }^{2}$, I Made Wirawan ${ }^{3}$, Samsul Hidayat ${ }^{4}$, Fachur \\ Rozy Dwi Septian ${ }^{5}$, Fiqhy Isrofil ${ }^{6}$
}

${ }^{1}$ Universitas Negeri Malang, Indonesia, email: muladi@um.ac.id

${ }^{2}$ Universitas Negeri Malang, Indonesia, email: yuni.rahmawati.ft@um.ac.id

${ }^{3}$ Universitas Negeri Malang, Indonesia, email: made.wirawan.ft@um.ac.id

${ }^{4}$ Universitas Negeri Malang, Indonesia, email: samsul.hidayat.fmipa@um.ac.id

5Universitas Negeri Malang, Indonesia, email: fachrur.rozi@student.um.ac.id

${ }^{6}$ Universitas Negeri Malang, Indonesia, email: fiqhy.isrofil@student.um.ac.id

*Koresponden penulis

\section{Info Artikel}

Diajukan: 25 Nov 2020

Diterima: 15 Apr 2021

Diterbitkan: 02 Mei 2021

Keywords:

oven; control; electronic; biscuit; capacity; quality

Kata Kunci:

oven; kontrol; elektronik;

bolu; kapasitas; kualitas

\section{Lisensi:}

cc-by-sa

\begin{abstract}
Community service with SME Sakinah Bakery is carried out to increase the production capacity and quality. Sakinah Bakery produces sponge cake and pastries that are very popular within the community and spread across 500 vendor shops in Malang City and Regency. Consumer demands has not been fully fulfilled due to low production capacity. About $10 \%$ of the product are undercooked or overcooked. These low quality products reduce the taste and aroma, breaks easily and becomes mushy quickly. Based on surveys and interviews, partner needs an large capacity oven that can produce well-cooked biscuits. The production tool that determine the cake ripeness is oven. This problem is overcomed by making an oven with electronic controls to stabilize the temperature and baking time. Temperature control with sensor feedback mounted on the combustion chamber forms a stable closed loop control system. Proper heating is obtained by controlling the LPG main valve. The three furnaces are spread out to get an even heating. The oven was able to increase $60 \%$ the production capacity per bake. The number of fail product decreases by $5.19 \%$ indicated that the product quality increases. Technology transfer in the form of training is carried out to maintain the quality.
\end{abstract}

\section{Abstrak}

Kegiatan pengabdian masyarakat dengan mitra UMKM Sakinah Bakery dilaksanakan untuk meningkatkan kapasitas dan kualitas produksi. Sakinah Bakery memproduksi bolu dan beberapa jenis kue kering yang digemari masyarakat dan tersebar di 500 toko penjual di Kota dan Kabupaten Malang. Permintaan konsumen belum seluruhnya dapat dipenuhi karena terkendala oleh kapasitas produksi yang rendah. Sekitar 10\% dari bolu yang diproduksi dalam kondisi kurang matang atau terlalu matang. Kualitas produk seperti ini menurunkan rasa dan aroma, mudah pecah dan cepat lembek. Berdasarkan survei dan wawancara, mitra memerlukan oven yang dapat menghasilkan bolu dengan kematangan sempurna dalam kapasitas yang besar. Alat produksi utama yang berpengaruh dominan pada kematangan kue bolu adalah oven. Masalah ini diatasi dengan membuat oven dengan kontrol elektronik untuk mengatur stabilitas suhu dan waktu pemanggangan. Kontrol suhu dengan 
umpan balik sensor yang dipasang pada ruang bakar membentuk sistem kontrol loop tertutup yang memberikan pengontrolan suhu yang stabil. Pemanasan yang tepat diperoleh melalui pengaturan katup utama LPG. Tiga tungku pembakar diletakkan tersebar untuk mendapatkan pemanasan yang merata. Oven yang dikembangkan telah mampu meningkatkan kapasitas produksi sebesar $60 \%$ per sekali masak. Kualitas produksi meningkat yang ditunjukkan oleh turunnya tingkat kegagalan produk sebesar 5.19\%. Alih teknologi berupa pelatihan dilakukan agar kualitas dapat dipertahankan.

\section{PENDAHULUAN}

Sakinah Bakery pada awalnya usaha rumah tangga yang memproduksi kue kering yang dipasarkan dan diperuntukan pada momen tertentu seperti hari raya. Seiring meningkatnya permintaan maka produksi jenis kue kering dilakukan secara reguler sebagai konsumsi sehari-hari dan tidak tergantung pada momen tertentu. Berbekal resep warisan dan hasil uji sampel yang memuaskan maka sejak tahun 2009 Sakinah Bakery memproduksi secara reguler bolu kering dengan nama dagang Bolu Senyum Barokah. Kapasitas produksi awal tidak besar karena hanya memiliki 2 orang karyawan. Permintaan pasar yang meningkat telah mendorong untuk meningkatkan kapasitas produksi sehingga memiliki 3 orang karyawan Selama 2 tahun berjalan, permintaan pasar terus meningkat namun karena terkendala tempat produksi maka kapasitas dipertahankan karena tidak memungkinkan untuk ditingkatkan. Lahan produksi yang lebih luas baru dapat dioperasikan pada tahun 2012. Lokasi produksi yang baru terpisah dengan lokasi produksi sebelumnya.

Pengembangan perusahaan baik secara internal dan eksternal senantiasa dijalankan sejak menempati lokasi yang baru. Standarisasi produksi menjadi salah satu yang dikembangkan melalui kontrol proses. Namun hasil yang diperoleh kurang memuaskan karena tidak didukung oleh mesin yang dapat dikontrol dengan baik. Bentuk, rasa dan kematangan menjadi faktor-faktor yang menentukan kualitas produk. Peningkatan kapasitas sumber daya manusia kembali ditingkatkan dengan merekrut 2 orang karyawan untuk bekerja di bagian pengiriman. Pasar yang tersebar luas membutuhkan mobilitas yang tinggi dan efisien. Pada proses pengiriman pada jarak yang cukup jauh seringkali terjadi kerusakan pada produk kue yakni patak atau remuk. Masalah ini telah dicoba diatasi dengan membuat kemasan dari kertas karton namun hasilnya kurang memuaskan.

Pengembangan perusahaan telah dilakukan dari sisi legal formal dengan pengurusan ijin PIRT dan sertifikasi halal seperti ditunjukkan pada Gambar 1. ljin ini sangat penting untuk meyakinkan konsumen bahwa produknya legal dan tidak berbahaya bagi kesehatan. Pengembangan eksternal juga dilakukan melalui ekspansi pasar yang lebih luas dan jalinan kerjasama dengan pemasok bahan baku. Upaya ini telah menampakkan hasil setelah 3 tahun dijalankan yang ditunjukkan oleh meningkatnya toko pelanggan yang menjual produk dari Sakinah Bakery. Saat ini jumlah toko pemasar sebanyak kurang lebih 500 toko yang terdiri dari toko kecil, menengah dan toko grosir. Interaksi dengan pihak-pihak luar khususnya 
dalam administrasi surat-menyurat, bukti pembayaran dan sebagainya, Sakinah Bakery telah membuat stempel untuk mendukung legalitas dokumen yang dikeluarkan.

Permasalahan yang dihadapi mitra saat ini adalah kualitas produk dan pengemasan produk. Kualitas produk yang dihasilkan belum standar, kematangan tidak merata bahkan ada yang gosong. Hal ini dikarenakan proses pemasakan dalam oven kurang terkontrol dengan baik karena dilakukan secara manual. Oven yang digunakan berupa oven dengan pemanas LPG tanpa perangkat kontrol apapun. Proses memasak berdasarkan waktu yang diperkirakan dengan jam manual.

Pengembangan alat produksi berupa mesin oven menggunakan gas elpiji yang dapat diatur secara otomatis menggunakan perangkat elektronik. Perangkat oven dapat dikontrol suhu, distribusi panas, dan waktunya. Kontrol dapat dilakukan dengan menggunakan sistem elektronik yang dapat bekerja secara otomatis. Pada awalnya kontrol dilakukan secara jarak jauh menggunakan smartphone melalui komunikasi wifi dengan teknologi loT(Qorni et al., 2018). Namun kontrol ini membutuhkan koneksi internet yang akan menambah biaya operasional perusahaan. Berdasarkan kesepakatan dengan mitra, kontrol jarak jauh digantikan dengan kontrol elektronik yang bekerja secara otomatis dan dioperasikan secara langsung. Kontrol elektronik memungkinkan suhu ruang masak akan terjaga stabil pada nilai yang ditetapkan. Demikian juga dengan pengaturan waktu dapat menjamin waktu memasak yang akurat dan konsisten sehingga menghasilkan kematangan yang tepat. Target yang akan dicapai adalah perangkat oven dengan kontrol suhu, distribusi panas, timer, serta alarm yang dapat bekerja secara otomatis. Dasar pengembangan oven merujuk kepada hasil penelitian (Astuti, 2015; Wihenti, 2017). Oven ini memiliki distribusi panas yang merata pada ruang masak sehingga menghasilkan kematangan kue yang merata pada seluruh bagian ruang bakar. Oven mampu menampung 150 buah kue bolu dalam sekali masak atau satu setengah kali kapasitas oven lama yang memuat 100 buah kue bolu.

Berdasarkan kebutuhan dari mitra industri, spesifikasi oven yang dibutuhkan adalah sebagai berikut. Oven menggunakan gas LPG sebagai sumber panas melalui kompor yang dipasang secara merata pada bagian bawah oven. Penyalaan api dilakukan secara otomatis melalui pemantik yang akan aktif ketika tombol Start ditekan. Demikian juga pengaturan nyala api dilakukan dengan mengatur katup gas yang dikendalikan secara elektronik berdasarkan suhu dan waktu yang ditentukan. Pengaturan suhu dan waktu dilakukan dengan cara memasukkan angka dari nilai yang diinginkan pada pengatur suhu dan timer. Alarm suara digunakan untuk memberitahukan jika waktu memasak sudah selesai. Spesifikasi fisik lainnya yang dibutuhkan oleh mitra adalah ukuran oven yang mampu menampung empat loyang berukuran $40 \times 70 \mathrm{~cm}$ dalam 2 lapis atau tray. Oven memiliki penyangga sehingga pintu ruang bakar pada posisi sejajar dengan pinggang atau tangan orang dewasa. Posisi akan memudahkan operator memasukkan dan mengeluarkan loyang ke dan dari ruang bakar. Bagian-bagian oven yang umumnya digunakan di 
industri kecil dan kontrol elektronik yang dapat disematkan pada oven akan dipaparkan berikut ini.

Sistem pembakaran menggunakan LPG dengan menggunakan satu tungku telah diatur oleh Menteri Perindustrian Nomor: 56/M-IND/PER/5/2009 Tanggal 28 Mei 2009 tentang Spesifikasi Teknik Kompor Gas Bahan Bakar LPG Satu Tungku Dengan Sistem Pemantik Mekanik Khusus Untuk Usaha Mikro (Peraturan Menteri Perindustrian RI, 2009). Sistem pemanas LPG terdiri dari kompor atau burner, regulator regulator, pemantik api, pipa gas dan tabung gas. Material burner harus tahan terhadap panas dan tidak mengalami perubahan bentuk saat digunakan. Standar material burner adalah baja tahan karat SUS 304 dengan ketebalan minimal $7 \mathrm{~mm}$. Ukuran burner baik pada kompor tekanan tinggi maupun tekanan rendah minimum adalah $\varnothing 90 \mathrm{~mm}$ (Peraturan Menteri Perindustrian RI, 2009). Model burner telah mengalami banyak dikembangkan melalui berbagai penelitian agar menghasilkan energi panas maksimum dari volume gas yang dibakar (Dinaryanto, 2010; Purwanto et al., 2005). Variasi jumlah lubang merupakan salah satu parameter yang menentukan efisiensi sebuah burner (Aditama \& Rohmawanto, 2014). Bentuk fisik dari burner juga telah mengalami perkembangan salah satunya dengan penambahan reflektor sirip untuk memaksimalkan pembakaran (Sudarno \& Fadelan, 2015). Berbagai jenis burner kecil digunakan pada kompor kecil dengan bidang pemanasan yang sempit seperti digunakan untuk keperluan rumah tangga. Burner besar digunakan pada kompor dengan bidang pemanasan yang luas sehingga pemanasan tersebar dengan merata. Burner besar digunakan pada industri makanan yang memasak makanan dalam jumlah besar (Taufan et al., 2013).

Pemanas LPG pada skala kecil dan pemanasan suhu rendah dengan lebih dari $3,5 \mathrm{~kW}$ dapat menggunakan regulator tekanan rendah yang dapat bekerja dapat bekerja pada tekanan gas minimum $2,8 \mathrm{kPa}(280 \mathrm{mmH} 2 \mathrm{O})$ dan maksimum $3,3 \mathrm{kPa}(330 \mathrm{mmH} 2 \mathrm{O})$. Sedangkan pada skala besar dan pemanasan tinggi di atas $9,0 \mathrm{~kW}$ dapat menggunakan regulator tekanan tinggi yang dapat bekerja pada tekanan gas maksimum 200kPa (Peraturan Menteri Perindustrian RI, 2009). Pemantik api pada kompor LPG terdiri dari 2 jenis yaitu pemantik mekanis dan pemantik elektrik namun keduanya memiliki persamaan yakni pembangkitan listrik tegangan tinggi pada dua logam berdekatan sehingga timbul loncatan bunga api. Sesaat sebelum percikan bunga api terjadi, katup gas terbuka sehingga gas LPG konsentrasi rendah berada di sekitar kedua logam. Percikan api menyulut gas dan kemudian menyalakan kompor.

Sistem kontrol elekronik terdiri dari dua jenis yaitu sistem kontrol terbuka dan sistem kontrol tertutup (Hidayat et al., 2018). Perbedaan kedua sistem terletak pada adanya umpan balik dari output ke input. Umpan balik ini digunakan sebagai informasi pengaturan yang lebih presisi (Niu et al., 2018). Pada oven elektronik, sistem kontrol tertutup dapat diaplikasikan dengan umpan balik berupa suhu ruang bakar yang akan mengendalikan katup gas yang akan menyuplai LPG ke burner. Diagram blok sistem ini ditunjukkan pada Gambar 1 berikut ini. 


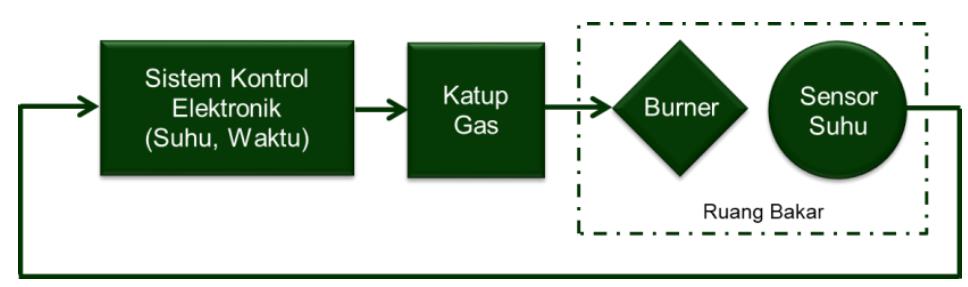

Gambar 1. Sistem kontrol elektronik tertutup pada oven

Komponen sistem kontrol elektronik yang digunakan untuk pengaturan suhu pada oven adalah sebagai berikut. Sensor suhu dipasang pada ruang bakar untuk memberikan informasi suhu kepada sistem kontrol elektronik. Suhu ruang bakar untuk memasak bolu kurang lebih $200^{\circ} \mathrm{C}$ (Wihenti, 2017) sehingga sensor yang digunakan harus mampu mengukur suhu diatas suhu ruang bakar dan tahan terhadap panas. Sensor suhu yang sesuai dengan kondisi ini adalah jenis thermocouple (Bashori et al., 2013; Nazarudin et al., 2018). Perangkat yang menerima informasi suhu dari sensor adalah pengontrol suhu yang diproduksi oleh Omron (Omron Inc., 2019). Alat ini akan mengirimkan sinyal perintah ON dan OFF ke katup gas elektronik berdasarkan perbandingan nilai suhu yang dimasukkan melalui tombol dengan suhu yang dikirimkan oleh sensor. Pengontrolan yang presisi sesuai skala industri diperlukan pada mesin oven agar diperoleh suhu pemanasan yang tepat dengan tingkat kesalahan yang rendah (Xie et al., 2015). Pengotrol suhu skala industri telah tersedia dalam bentuk modul yang siap diimplementasikan (Yadav \& Narayanankutty, 2011). Suhu yang diinginkan pada ruang bakar dimasukkan melalui tombol naik dan turun yang berada di bawah layar konsol. Pengontrol suhu akan mengendalikan katup LPG yang akan membuka jika suhu ruang bakar lebih rendah dari suhu yang diinginkan dan sebaliknya akan menutup ketika suhu ruang bakar sama dengan suhu yang dibutuhkan.

Pengaturan waktu pembakaran pada proses memasak bolu sangat penting karena akan menentukan tingkat kematangan yang tepat (Wihenti, 2017). Akurasi alat pengaturan waktu ini menentukan kualitas produk yang dimasak dan efisiensi penggunaan LPG. Pengatur waktu akan mengirimkan sinyal ke katup gas elektronik untuk membuka dan menutup serta mengirimkan sinyal alarm jika waktu yang ditentukan sudah tercapai. Spesifikasi yang penting dari pengatur waktu untuk mesin oven adalah akurasinya sehingga digunakan pengatur waktu standar industri (Yadav \& Narayanankutty, 2011). Kombinasi penggunaan sensor suhu dan pengaturan waktu standar industri akan menhasilkan pengontrolan proses memasak yang presisi dan akurat.

\section{METODE PELAKSANAAN}

Pengembangan alat produksi berupa mesin oven untuk pemanggang bolu dilaksanakan dalam beberapa tahap yakni tahap identifikasi masalah dan kebutuhan, perancangan alat, pengembangan alat, uji coba dan revisi, dan uji penggunaan. Tahapan pengembangan ditunjukkan pada oleg diagram alir 
pada Gambar 2. Tahap pertama yakni identifikasi masalah dan kebutuhan dari mitra industri dilaksanakan dengan melalui wawancara. Permasalahanpermasalahan yang dihadapi dalam operasional usaha dikelompokkan berdasarkan sumber masalah dan dampaknya terhadap kelangsungan usaha. Tahap ini dilaksanakan sebelum kegiatan pengabdian ini diajukan. Berdasarkan hasil wawancara dan analisis informasi, permasalahan yang dapat dibantu diatasi dalam program pengabdian adalah pengembangan alat produksi berupa oven. Permasalahan yang hendak diselesaikan dengan adanya oven ini peningkatan kualitas produksi yakni tingkat kematangan yang kurang merata pada bolu yang dihasilkan. Pengembangan oven juga bertujuan untuk meningkatkan kapasitas produksi.

Tahap kedua adalah perancangan alat oven sesuai dengan identifikasi permasalahan yang ditemukan pada proses produksi mitra. Perancangan dilaksanakan bersama mitra dengan menentukan spesifikasi alat, survei perbandingan dengan mesin oven yang telah dimiliki dan oven yang tersedia di pasaran, dan menentukan sistem kontrol elektronik yang digunakan. Perancangan alat juga mempertimbangkan besarnya biaya produksi tambahan yang disebabkan oleh penggunaan alat baru. Tahap berikutnya adalah pengembangan alat yang terdiri dari dua kelompok pekerjaan yaitu pekerjaan mekanis dan pekerjaan elektronik. Pekerjaan mekanis meliputi kerja-kerja logam dan las dalam pembuatan rangka dan bodi mesin oven. Pekerjaan ini membutuhkan keahlian yang tidak dimiliki oleh anggota tim sehingga menggunakan tenaga profesional berpengalaman untuk membantu penyelesaiannya. Pekerjaan elektronik meliputi instalasi sistem pemanas elpiji beserta sistem kontrol elektronik. Hasil perancangan sistem kontrol elektronik mesin oven ditunjukkan pada Gambar 3. Suhu dalam ruang bakar diukur menggunakan sensor suhu jenis thermocouple. Sinyal yang dihasilkan oleh thermocouple dimasukkan ke pengontrol suhu yang membandingkan sinyal dari thermocouple dengan nilai yang diinputkan oleh operator. Jika kedua nilai sama maka kontrol suhu akan mengeluarkan sinyal yang dikirimkan ke kontrol utama. Kontrol utama akan menggunakan sinyal ini untuk menaikkan atau menurunkan jumlah gas yang keluarkan oleh katup utama gas. Kontrol utama juga mengatur katup-katup distribusi pada masing-masing burner. Kontrol utama juga menerima sinyal dari Timer yang akan digunakan untuk membuka atau menutup katup utama dan menyalakan pemantik pada setiap burner. Kontrol suhu dan timer menggunakan perangkat kontrol standar industri yang mempunyai presisi dan akurasi tinggi serta lolos uji industri.

Tahap uji coba dilakukan dalam dua tahap yakni uji coba tanpa bolu dan uji coba dengan bolu. Uji coba tanpa bolu bertujuan untuk mengetahui cara kerja alat dan dievaluasi berdasarkan spesifikasi perancangan yang dibuat. Uji coba dilakukan dengan menggunakan adonan bolu untuk menentukan pengaturan kontrol yang tepat agar bolu yang dihasilkan dapat matang dengan sempurna dan merata. Pengaturan suhu, pewaktuan, penempatan sensor, pengaturan pemanas, penempatan nampan, alarm dan instalasi listrik dilakukan dalam uji coba ini. Setelah melakukan serangkaian uji coba dan mendapatkan hasil yang memuaskan, uji coba penggunaan 
dilakukan dengan kapasitas penuh dan terus menerus selayaknya proses produksi normal. Pada tahap uji penggunaan ini prosedur pengoperasian mesin oven dievaluasi berdasarkan produk yang dihasilkan. Metode yang digunakan dalam melakukan kegiatan pengabdian ini ditunjukkan pada Gambar 2.

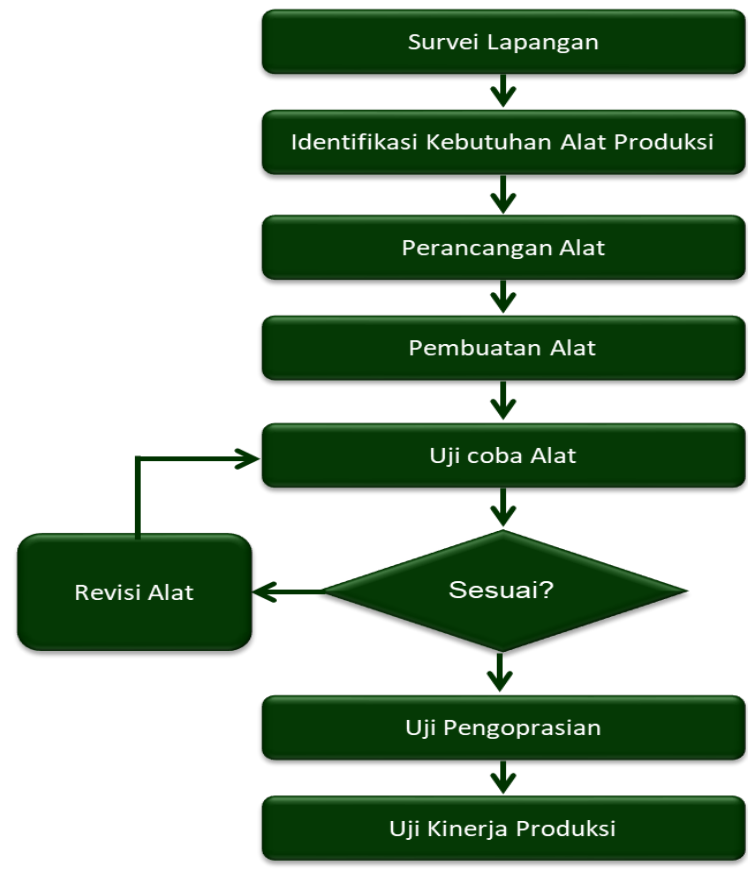

Gambar 2. Diagram alir kegiatan pengembangan alat produksi

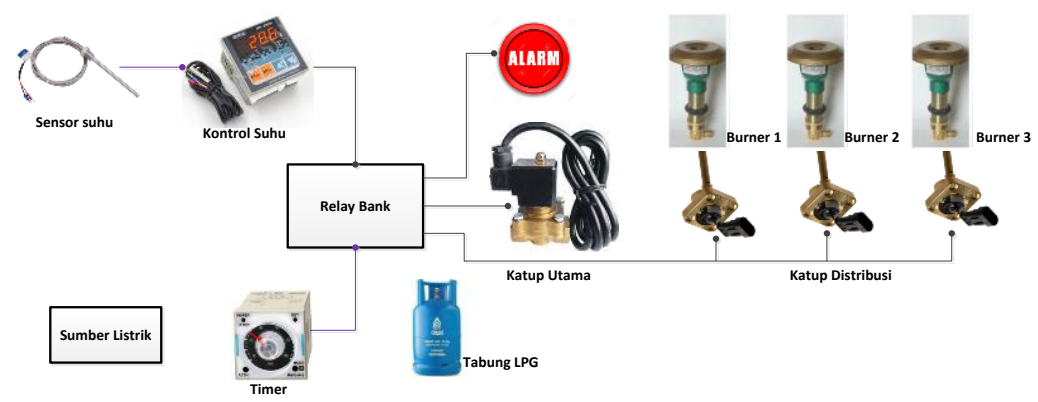

Gambar 3. Diagram rangkaian elektronik sistem kontrol mesin oven

\section{HASIL DAN PEMBAHASAN}

Deskripsi mesin oven yang telah dibuat secara garis besar diuraikan sebagai berikut. Mesin oven memilik ukuran panjang $80 \mathrm{~cm}$, lebar $100 \mathrm{~cm}$ dan tinggi $80 \mathrm{~cm}$ ditambah dengan penyangga setinggi $80 \mathrm{~cm}$ dengan rangka dan bodi yang terbuat dari baja tahan karat dengan ketebalan $1 \mathrm{~mm}$. Ruang bakar oven terdiri dari dua lapis dinding baja terpisah $3 \mathrm{~cm}$ yang disekat dengan menggunakan glass wool. Tujuan penggunaan dinding ganda berpenyekat 
glass wool adalah untuk mencegah emisi panas dari ruang bakar keluar melalui dinding. Panas yang keluar dari ruang bakar disamping menyebabkan ruang di sekitar panas juga menyebabkan pemborosan dalam penggunaan gas karena untuk menjaga suhu ruang bakar stabil maka kompor pemanas terus menerus menyala. Mesin oven terdiri dari 3 kompor pemanas menggunakan burner berukuran diameter $20 \mathrm{~cm}$ yang masing-masing dilengkapi dengan regulator tambahan dan pemantik elektronik. Ketiga kompor disuplay LPG melalui satu pipa besi yang dihubungkan dengan selang karet ke katup gas elektronik. Suplai LPG yang berasal dari tabung LPG dimasukkan ke katup utama melalui pipa karet. Katup gas elektronik dikendalikan secara elektronik oleh kontrol utama berdasarkan sinyal dari kontrol suhu dan timer. Pengaturan suhu dilakukan melalui pengontrol suhu yang mendapatkan input dari tombol penginput suhu dan sinyal dari sensor thermocouple yang sekaligus berfungsi sebagai umpan balik sistem kontrol. Sketsa fisik rancangan mesin oven ditunjukkan pada Gambar 4.

Realisasi rancangan mesin oven menggunakan bahan-bahan berkualitas tinggi agar mesin dapat bekerja dengan benar dan dapat dikontrol sesuai kebutuhan serta tahan lama. Alat dan bahan mengacu pada Standar Kompor untuk UKM (Peraturan Menteri Perindustrian RI, 2009) sehingga mesin ini memenuhi Standar Nasional Indonesia (SNI). Peralatan kontrol elektronik menggunakan perangkat standar industri seperti diuraikan dalam kajian pustaka dan tahapan pengembangan. Kontrol elektronik menggunakan daya listrik dengan tegangan $220 \mathrm{~V}$ AC dan modul penyearah daya rendah untuk mencatu kontrol utama. Spesifikasi mesin oven yang dihasilkan sesuai dengan spesifikasi mesin hasil perancangan.

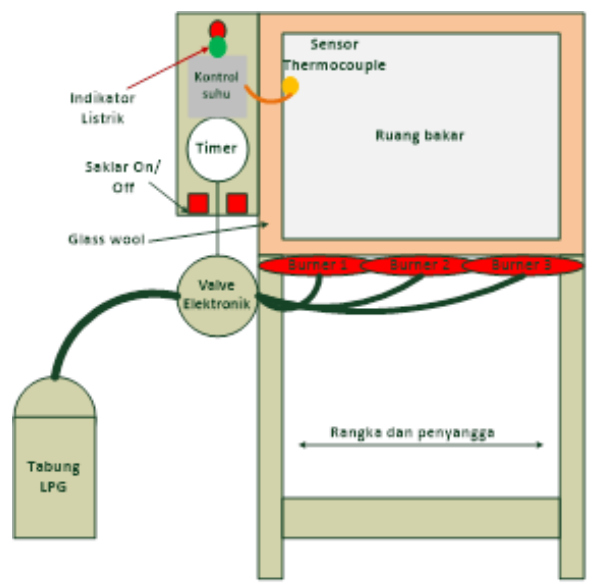

Gambar 4. Sketsa rancangan mesin oven

Pembuatan alat dimulai dengan pembuatan gambar teknis alat yang mendefinisikan dengan detil dimensi oven yang dibutuhkan. Sesuai dengan observasi dan wawancara dengan mitra, oven yang dibutuhkan terdiri dari dua tingkat atau $60 \mathrm{~cm}$ dan masing-masing tingkat mampu memuat dua nampan berukuran $30 \times 40 \mathrm{~cm}$ yang masing-masing dapat menampung 40 kue dan total 
160 kue dalam sekali masak atau $60 \%$ lebih banyak per sekali masak. Ukuran tersebut ditambah dengan ruangan untuk sirkulasi panas dari bawah ke sekeliling ruang bakar, ruang sekat agar panas tidak merambat ke dinding luar oven, ruang untuk instalasi perangkat kontrol, ruangan pemanas yang berisi tungku kompor dan pemantik, serta katup pengatur aliran gas. Dimensi luar adalah sebagai berikut panjang $80 \mathrm{~cm}$, tinggi $80 \mathrm{~cm}$ dan lebar $60 \mathrm{~cm}$. Dimensi ini menghasilkan volume ruang bakar sebesar 144 liter. Kompor, pemantik dan katup beserta pipa untuk aliran LPG ditaruh di luar bagian bawah badan oven. Perangkat elektronik yang digunakan adalah perangkat kontrol industri dengan lingkungan kerja bersuhu kurang dari 50oC sehingga perangkat ini diletakkan bagian samping dari badan oven. Agar oven dapat dioperasikan secara ergonomis sesuai ukuran badan kebanyakan orang Indonesia, maka badan oven diletakkan di atas penyangga tetap setinggi $80 \mathrm{~cm}$.

Proses pembuatan diawali dengan pembuatan badan oven dan dudukan yang terbuat dari baja tahan karat. Pemotongan logam, pengelasan dan perakitan logam dilakukan di bengkel logam dengan dibantu oleh teknisi yang berpengalaman dalam pengerjaan logam. Proses pengerjaan logam di bengkel ditunjukkan pada Gambar 5. Foto mesin oven yang dihasilkan diperlihatkan pada Gambar 6. Pada gambar ini terdapat pantulan obyek didepan mesin oven karena bodi mesin terbuat dari baja anti karat yang mengkilat agar mudah dibersihkan.

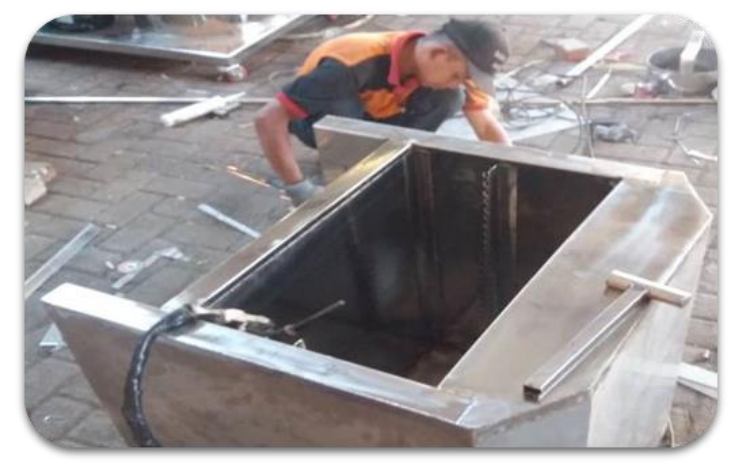

Gambar 5. Proses pembuatan oven

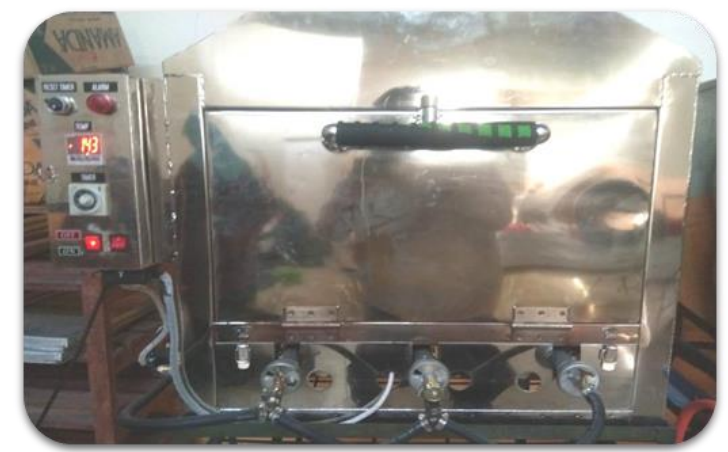

Gambar 6. Hasil akhir oven 
Oven yang sudah dirakit diuji coba sebelum digunakan pada proses produksi. Hal ini perlu dilakukan untuk memperoleh pengaturan pemanasan dan pewaktuan yang tepat sehigga dihasilkan produk yang berkualitas tinggi yakni kematangan tepat dan merata. Kendala yang dihadapi oleh mitra industri selama ini adalah kematangan produk bolu yang tidak merata dengan sempurna yang disebabkan oleh kurang meratanya proses pemanggangan pada oven. Uji coba dilakukan dengan melakukan proses memasak kue bolu dengan menggunakan oven baru dan oven lama. Keberhasilan proses memasak ditunjukkan oleh jumlah kue yang masak sempurna dan sebaliknya kegagalan produksi disebabkan oleh kue yang kurang matang atau terlalu matang. Tabel 1 menunjukkan perbandingan hasil memasak kue bolu menggunakan oven baru dengan kapasitas 160 kue dan oven lama dengan kapasitas 100 kue. Kegagalan dalam 20 kali percobaan menunjukkan bahwa oven baru dengan kontrol elektronik rata-rata sebanyak 7,45 buah atau $4,66 \%$ dan oven lama sebanyak 9,85 buah atau $9,85 \%$. Terdapat penurunan tingkat kegagalan produksi dari oven lama ke oven baru yaitu sebesar $5,19 \%$.

Tabel 1. Perbandingan hasil memasak kue bolu oven baru dan oven lama

\begin{tabular}{|c|c|c|c|c|c|c|c|c|}
\hline \multirow{3}{*}{ No } & \multicolumn{4}{|c|}{ Oven Baru } & \multicolumn{4}{|c|}{ Oven Lama } \\
\hline & \multirow{2}{*}{ Kapasitas } & \multicolumn{2}{|c|}{ Kualitas } & \multirow[b]{2}{*}{$\%$ Gagal } & \multirow{2}{*}{$\begin{array}{l}\text { Kapasitas } \\
\text { Sempurna }\end{array}$} & \multicolumn{2}{|c|}{ Kualitas } & \multirow[b]{2}{*}{$\%$ Gaga } \\
\hline & & Sempurna & Gagal & & & Sempurna & Gagal & \\
\hline 1 & 160 & 152 & 8 & $5,00 \%$ & 100 & 90 & 10 & $10,00 \%$ \\
\hline 2 & 160 & 151 & 9 & $5,63 \%$ & 100 & 92 & 8 & $8,00 \%$ \\
\hline 3 & 160 & 151 & 9 & $5,63 \%$ & 100 & 88 & 12 & $12,00 \%$ \\
\hline 4 & 160 & 154 & 6 & $3,75 \%$ & 100 & 90 & 10 & $10,00 \%$ \\
\hline 5 & 160 & 151 & 9 & $5,63 \%$ & 100 & 91 & 9 & $9,00 \%$ \\
\hline 6 & 160 & 153 & 7 & $4,38 \%$ & 100 & 90 & 10 & $10,00 \%$ \\
\hline 7 & 160 & 151 & 9 & $5,63 \%$ & 100 & 89 & 11 & $11,00 \%$ \\
\hline 8 & 160 & 154 & 6 & $3,75 \%$ & 100 & 91 & 9 & $9,00 \%$ \\
\hline 9 & 160 & 152 & 8 & $5,00 \%$ & 100 & 88 & 12 & $12,00 \%$ \\
\hline 10 & 160 & 152 & 8 & $5,00 \%$ & 100 & 91 & 9 & $9,00 \%$ \\
\hline 11 & 160 & 154 & 6 & $3,75 \%$ & 100 & 88 & 12 & $12,00 \%$ \\
\hline 12 & 160 & 152 & 8 & $5,00 \%$ & 100 & 91 & 9 & $9,00 \%$ \\
\hline 13 & 160 & 153 & 7 & $4,38 \%$ & 100 & 90 & 10 & $10,00 \%$ \\
\hline 14 & 160 & 152 & 8 & $5,00 \%$ & 100 & 91 & 9 & $9,00 \%$ \\
\hline 15 & 160 & 153 & 7 & $4,38 \%$ & 100 & 91 & 9 & $9,00 \%$ \\
\hline 16 & 160 & 154 & 6 & $3,75 \%$ & 100 & 89 & 11 & $11,00 \%$ \\
\hline 17 & 160 & 151 & 9 & $5,63 \%$ & 100 & 90 & 10 & $10,00 \%$ \\
\hline 18 & 160 & 154 & 6 & $3,75 \%$ & 100 & 90 & 10 & $10,00 \%$ \\
\hline 19 & 160 & 154 & 6 & $3,75 \%$ & 100 & 92 & 8 & $8,00 \%$ \\
\hline \multirow[t]{2}{*}{20} & 160 & 153 & 7 & $4,38 \%$ & 100 & 91 & 9 & $9,00 \%$ \\
\hline & \multicolumn{2}{|c|}{ Rata-rata } & 7,45 & $4,66 \%$ & \multicolumn{2}{|c|}{ Rata-rata } & 9,85 & $9,85 \%$ \\
\hline
\end{tabular}

Sistem kontrol elektronik tertutup yang diimplementasikan pada mesin oven ini berbeda dengan mesin oven yang selama ini digunakan di mitra industri. Pengoperasian oven yang baru sedikit berbeda sehingga diperlukan pelatihan sebagai sarana alih teknologi kepada mitra dalam hal ini pemilik dan para karyawan. Pelatihan dilakukan agar proses produksi dapat menghasilkan produk yang berkualitas diantaranya meliputi pengoperasian kontrol elektronik, kontrol katup manual, pemantik otomatis, cara membaca tampilan kontrol, memahami arti alarm, dan keselamatan kerja. Kegiatan pelatihan pengoperasian oven dengan kontrol elektonik ditunjukkan pada Gambar 7. 


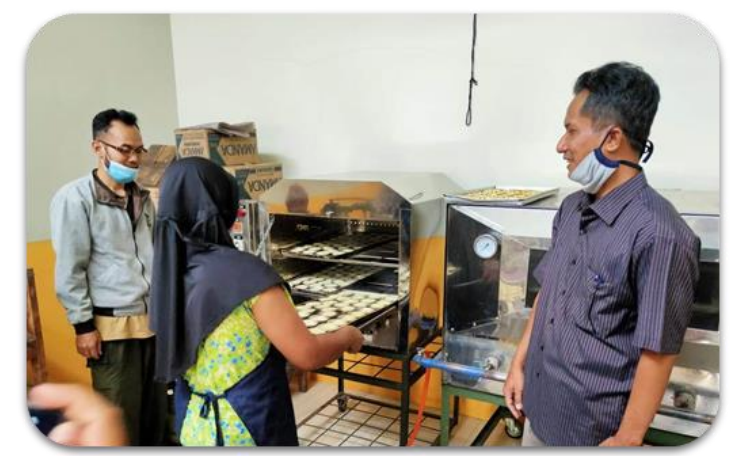

Gambar 7. Pelatihan pengoperasian oven kepada karyawan

\section{KESIMPULAN}

Kegiatan pengabdian masyarakat dengan mitra industri Sakinah Bakery dilaksanakan melalui pengembangan alat produksi berupa oven dengan kontrol elektronik tertutup. Pengembangan alat ini bertujuan untuk meningkatkan kapasitas dan kualitas produksi berupa bolu kering. Kapasitas produksi dapat ditingkatkan dengan penggunaan oven dengan kapasitas ruang bakar yang besar. Kendala untuk menghasilkan produk dengan kematangan yang merata dapat diatasi dengan penurunan persentase yang signifikan. Alih teknologi telah dilakukan melalui kegiatan pelatihan pengoperasian oven kepada mitra industri bersama dengan karyawannya. Kegiatan abdimas ini telah membantu penyelesaian masalah yang dihadapi oleh mitra industri.

Pada masa pandemi COVID19, proses produksi dituntut untuk meminimalkan interaksi antar manusia maupun interaksi manusia dengan alat dan hasil produksi. Produk olahan makanan perlu melaksanakan ketentuan ini karena produknya akan masuk secara langsung ke tubuh manusia, sehingga dalam proses produksi diupayakan sentuhan langsung manusia ke produk dan kemasan perlu diminimalkan. Kemampuan usaha kecil untuk mengadakan peralatan untuk mementuhi ketentuan tersebut sangat terbatas sehingga perlu diadakan kegiatan pengabdian lanjutan agar usaha kecil tetap dapat beroperasi di masa pandemi ini dengan produk yang aman dari penyebaran COVID19.

\section{UCAPAN TERIMA KASIH}

Ucapan terima kasih bisa disampaikan kepada Universitas Negeri Malang melalui Lembaga Penelitian dan Pengabdian kepada Masyarakat (LP2M) yang telah mendanai kegiatan pengabdian masyarakat ini melalui PNBP Tahun 2020.

\section{DAFTAR RUJUKAN}

Aditama, F., \& Rohmawanto, S. (2014). Variasi Jumlah Lubang Burner Terhadap Efisiensi Kompor Gas Bahan Bakar LPG Satu Tungku dengan Sistem Pemantik Mekanik. Berita Litbang Industri, 3(2), 63-66. http://ejournal.kemenperin.go.id/blisby/article/view/579 
Astuti, R. M. (2015). Pengaruh Suhu Pengovenan Terhadap Kualitas Roti Manis Dilihat Dari Aspek Warna Kulit, Rasa, Aroma dan Tekstur. Teknoboga: Jurnal Teknologi Busana Dan Boga, 2(2), 61-79. https://doi.org/https://doi.org/10.15294/teknobuga.v2i2.6433

Bashori, Z., Sumardi, \& Setiawan, I. (2013). Pengendalian Temperatur pada Plant Sederhana Electric Furnace Berbasis Sensor Thermocouple dengan Metode Kontrol PID. Transient: Jurnal Teknik Elektro, 2(1), 18. https://doi.org/https://doi.org/10.14710/transient.2.1.1-8

Dinaryanto, O. (2010). Pengaruh jenis burner terhadap konsumsi bahan bakar Ipg. Angkasa: Jurnal IImiah Bidang Teknologi, 2(1), 77-84.

Hidayat, D., Rahmatika, M., Syafei, N. S., \& Tumbelaka, B. Y. (2018). Simulasi Pengontrol On/Off pada Sistem Kendali Umpan Balik dengan Model Fisis Elektronik. TELKA - Telekomunikasi, Elektronika, Komputasi Dan Kontrol, 4(1), 43-53. https://doi.org/10.15575/telka.v4n1.43-53

Nazarudin, D. A. A., Nordin, M. K., Ahmad, A., Masrie, M., Saaid, M. F., Thamrin, N. M., \& Ali, M. S. A. M. (2018). Evaluation of RTD and thermocouple for PID temperature control in distributed control system laboratory. Journal of Fundamental and Applied Sciences, 9(6S), 600. https://doi.org/10.4314/jfas.v9i6s.45

Niu, Z., Zhao, Y., Hu, J., Wang, D., Dong, L., \& Wang, L. (2018). Explore the Development and Application of Electrical Automation Control Systems. Smart Construction Research. https://doi.org/10.18063/scr.v2i4.621

Omron Inc. (2019). Technical Explanation for Temperature Sensors.

Purwanto, W. W., Basuki, A. S., \& Rahmayani, S. N. (2005). Perancangan Burner Untuk Meningkatkan Kinerja Pembakaran Kompor Gas LPG. REAKTOR, 9(2),

67-72. https://doi.org/https://doi.org/10.14710/reaktor.9.2.67-72 View

Qorni, W. Al, Azhar, A., \& Yuniarti, E. (2018). Perancangan Sistem Kontrol Otomatis Berbasis Web Menggunakan Raspberry $\mathrm{Pi} 3$ pada Smarthome. Al-Fiziya: Journal of Materials Science, Geophysics, Instrumentation and Theoretical Physics, 1(2), 15-24. https://doi.org/10.15408/fiziya.v1i2.9501

Peraturan Menteri Perindustrian RI, Pub. L. No. 56/M-IND/PER/5/2009, 28 Mei 200 (2009).

Sudarno, \& Fadelan. (2015). Peningkatan Efisiensi Kompor LPG Dengan Menggunakan Reflektor Radiasi Panas Bersirip. Jurnal Ilmiah Semesta Teknika, 18(1),

94-105. https://journal.umy.ac.id/index.php/st/article/view/710

Taufan, A., Novrinaldi, \& Hanifah, U. (2013). Design, Construction and Test of Gas Stove for Traditional Tofu Industry Based on Cleaner Production. Agritech, 33(4), https://doi.org/https://doi.org/10.22146/agritech.9540

Wihenti, A. (2017). Analisis Kadar Air, Tebal, Berat, Dan Tekstur Biskuit Cokelat Akibat Perbedaan Transfer Panas. Jurnal Aplikasi Teknologi Pangan, 6(2), 69-73. https://doi.org/10.17728/jatp.186 
Xie, D., Chang, X., Shu, X., Li, L., Wang, J., Mei, L., \& Liu, Y. (2015). High precision temperature control system for an Oven-Controlled crystal oscillator. Open Automation and Control Systems Journal, 7(1), 16901697. https://doi.org/10.2174/1874444301507011690

Yadav, S. G., \& Narayanankutty, K. A. (2011). A Versatile Industrial Timer and Real Time Keeper. Wireless Engineering and Technology, 2(3), 196203. https://doi.org/10.4236/wet.2011.23027 